\title{
The Attitudes of Medical Students towards Problem-Based Learning during the Clinical Years
}

\author{
Treesirichod, $A^{1}$, Chansakulporn, $S^{2}{ }^{2}$, Phivthong-ngam, $L^{3}{ }^{3}$, Kusumaphanyo, $C^{4}$, \\ Sangpanich, $A^{5}$
}

\begin{abstract}
Introduction: Multiple learning tools have been used in education during the clinical years. Problembased learning (PBL) is one of the learning strategies that has currently been introduced into curriculums. The success of PBL in the preclinical year has been reported on globally.

Objective: This study's aim was to assess the attitudes and knowledge of the students in their clinical year of PBL.

Methods: The study was conducted among 387 clinical year medical students at the Faculty of Medicine, Srinakharinwirot University, Thailand. Self-administered questionnaires were used to determine the attitudes and knowledge that had resulted.

Results: The overall response rates were at $76.0 \%$. Regarding the opinion of medical students toward PBL, the majority of them agree that PBL develops their communication skills (91.4\%), skills necessary for working as a team (91.0\%), competence in self-directed learning (91.4\%), and enhances the information inquiry skills $(89.0 \%)$. The majority of the students $(76.8 \%)$ indicated that they appreciated PBL although it was time consuming (48.9\%) and stressful (44.8\%). Regarding the comprehension of PBL, $76.5 \%$ of the medical students had the misunderstanding that PBL requires knowledge obtained from conventional lectures. In comparison to other learning tools; the students have agreed that PBL is better than conventional lectures (41.8\%) and report writing (62.8\%).
\end{abstract}

Conclusion: The results indicate that clinical students have positive attitudes toward PBL and that the curriculum should integrate PBL with other learning strategies.

Key Words: Attitude, Medical student, Problem-based learning, Clinical year

\section{Introduction}

Problem-based learning (PBL) is a studentcentered approach that challenges learners to apply basic knowledge to expand an interchangeable solution through a problem (Albanese \& Mitchell, 1993).

\footnotetext{
${ }^{1,2,3,4,5}$ Faculty of Medicine, Srinakharinwirot University, Bangkok, Thailand.

Corresponding Author:

Arucha Treesirichod, Department of Pediatrics, Faculty of Medicine, Srinakharinwirot University, $\mathrm{HRH}$ Princess Maha Chakri Sirindhorn medical center, Rangsit-Nakhonnayok Road,

Ongkharak, Nakhonnayok 26120 ,

Thailand.

E-mail:Trees_ar@yahoo.com
}

PBL not only provides learners more opportunities for the application of knowledge for problem solving but also facilitates a wide range of skills and attitudes. Some of these are communication, listening, presentation, team work, taking responsibility, self-directed learning and the critical evaluation of literature (Wood, 2003). Meanwhile, PBL also has limitations as experienced facilitators are needed (Lin, 2005), it is time consuming and requires large numbers of staff and learning resources (Wood, 2003). Although there are many studies that have reported on the achievements of $\mathrm{PBL}$ as compared to conventional teaching (Schmidt et al., 2006; Nandi et al., 2000; Preeti et al., 2013), there

DOI: http://doi.org/10.4038/seajme.v12i1.41 
are reports of controversies in the results (Hartling et al., 2010; Colliver, 2000).

Twenty-two years of outcome research in preclinical medical education had shown evidence that PBL does not provide explicit support for enhanced learning (Hartling et al., 2010). There are many factors that have impacted the accomplishments of PBL. The role played by the facilitator, the learning process and environment, scenario writing, the structures of small groups and an appropriate assessment process (Newman, 2005). The attitude of the learners and the tutors were also important factors in the keys for success (Wood, 2003; Hatthachote et al., 2008). The report of the attitude and knowledge of medical instructors toward PBL in Thailand show that $53.1 \%$ had the correct knowledge of PBL and the knowledge of PBL concepts were significantly associated with a favourable attitude (Hatthachote et al., 2008). Likewise, an acceptance of PBL among medical students is crucial in regards to successful learning (Ratzmann et al., 2013).

Recently, PBL has been widely implemented into the undergraduates, curriculum. PBL has been endorsed by medical schools, especially in the preclinical year, here in Thailand. In the clinical year curriculum, there are a wide range of teaching tools that are utilized. Some of these are such as lecture-based learning, case-based learning, self-directed learning, report writing, teaching rounds and clinical ward rounds. At our Faculty, PBL is also one of the learning strategies that has been adopted into the curriculum for both; the preclinical and clinical years. With the conflicting evidence and limitations of PBL (in particular, that it is timeconsuming) (Hartling et al., 2010), the appropriateness of PBL for teaching in the clinical year is questionable. Only a few studies conducted on clinical year education have been done in regards to PBL. Therefore this study's aim is to assess the attitudes and knowledge of clinical year students on the method of PBL.

\section{Methods}

The study was conducted among 387 clinical year medical students at the Faculty of Medicine, Srinakharinwirot University, Thailand. This study was reviewed and approved by the appropriate institutional review boards and the ethics committee of Srinakharinwirot University.

According to the existing teaching approach, PBL has been implemented into the curriculum for clinical years along with the conventional teaching. Problem-based scenario was selected based on actual clinical cases varies on learning objectives and the background knowledge of the students. PBL tutorial was held as a group study, divided into 3 sessions in the period of 2 consecutive weeks. The learning process starting with the scenario (problem) serves as a trigger for learning. The students elaborate on each stimulus for problem identification, hypothesis generation and came out with a list of learning issues in the first session. The second session, the students will be spending time for review of learning topics identified in the previous session, present their findings, discuss supplementary resources, and refine the hypothesis. In this session, inquiry plan and information gathering skill will be encouraged to identify the specific clinical information needed about the patient in order to reach a diagnosis. The last session was conducted for summarizing the whole process of proper diagnosis based on evidence and opening to discuss the difficulties issues and clear any remaining uncertainties. During each session the students will be spending time for searching data and meet the expert to solving the problem.

Self-administered questionnaires were used to determine attitudes and knowledge regarding $\mathrm{PBL}$. The research questionnaire collected the following data; demographic information [age, gender, grade point average (GPA), study year] and a five-point Likert scale (strongly agree, agree, neither agree nor disagree, disagree, strongly disagree) on the students attitudes toward PBL. Aspects of the attitudes of PBL consisted of an opinion survey that covered academic performance, time effectiveness, the impact on the learner, interpersonal skills, communication skills, and the students' overall attitude toward PBL.

A 10 item questionnaire with a three-point scale per question (agree, undecided, disagree) was used to assess the knowledge of PBL. Each item was scored as 1 point if the students' answer matched with the correct answer. The total score obtainable for 
knowledge of PBL is 10. Statistical analysis was performed using SPSS from IBM Singapore Pte Ltd (Registration No. 197501566-C)

The findings were analyzed using descriptive statistics. The relationship between the attitude, the knowledge of PBL and each potential variable was explored. A p-value of less than 0.05 would be considered statistically significant.

\section{Results}

A total of 387 medical students participated in the study. The overall response rate was $76.0 \%$. The majority of them were female $(59.5 \%)$. The average age of respondents was 22.7 years (18-30 years of age). The average grade point average was 3.31 (2.21-3.98). The respondents were fourth, fifth and sixth year medical students with rates of $33.7 \%, 35.7 \%$ and $30.6 \%$ respectively.

Table 1:The attitude of medical students toward PBL

\begin{tabular}{|c|c|c|c|c|c|}
\hline & $1(\%)$ & $2(\%)$ & $3(\%)$ & $4(\%)$ & $5(\%)$ \\
\hline \multicolumn{6}{|l|}{ Academic performance } \\
\hline $\begin{array}{l}\text { The learner achieves the knowledge according } \\
\text { to the standard medical competency }\end{array}$ & $30(10.2)$ & $216(73.5)$ & $25(8.5)$ & $21(7.1)$ & $2(0.7)$ \\
\hline Better retention of knowledge & $54(18.4)$ & $164(55.4)$ & $40(13.6)$ & $33(11.2)$ & $3(1.0)$ \\
\hline Develops information inquiry skills & $56(19.0)$ & $206(70.1)$ & $26(8.8)$ & $5(1.7)$ & $1(0.3)$ \\
\hline Develops the critical thinking skills & $57(19.4)$ & $179(60.9)$ & $41(13.9)$ & $16(5.4)$ & $1(0.3)$ \\
\hline Improve the active learning & $44(15.0)$ & $184(62.6)$ & $42(14.3)$ & $22(7.5)$ & $2(0.7)$ \\
\hline Develops the self-directed learning skills & $64(21.8)$ & $205(69.7)$ & $18(6.1)$ & $7(2.4)$ & $0(0)$ \\
\hline \multicolumn{6}{|l|}{ Time efficiency } \\
\hline Using time effectively for knowledge gained & $22(7.5)$ & $176(59.9)$ & $58(19.7)$ & $36(12.2)$ & $2(0.7)$ \\
\hline The self-study is time consuming process & $21(7.1)$ & $123(41.8)$ & $69(23.5)$ & $74(25.2)$ & $7(2.4)$ \\
\hline Decreases the time for patients care & $12(4.1)$ & $75(25.5)$ & $61(20.7)$ & $125(42.5)$ & $21(7.1)$ \\
\hline \multicolumn{6}{|l|}{ The impact on the learner } \\
\hline Reduce stress & $13(4.4)$ & $75(25.5)$ & $74(25.2)$ & $113(38.4)$ & $19(6.5)$ \\
\hline Improves the ability to express opinions & $40(13.6)$ & $187(63.6)$ & $38(12.9)$ & $26(8.8)$ & $3(1.0)$ \\
\hline Increases the individual responsibility & $46(15.6)$ & $185(62.9)$ & $41(13.9)$ & $19(6.5)$ & $3(1.0)$ \\
\hline Make the learner more confident & $20(6.8)$ & $84(28.6)$ & $73(24.8)$ & $106(36.1)$ & $11(3.7)$ \\
\hline Increases the self-study skills & $56(19.0)$ & $204(69.4)$ & $29(9.9)$ & $5(1.7)$ & $0(0)$ \\
\hline Develops the listening skills & $51(17.3)$ & $218(74.1)$ & $19(6.5)$ & $4(1.4)$ & $2(0.7)$ \\
\hline Develops the leadership skills & $36(12.2)$ & $196(66.7)$ & $45(15.3)$ & $16(5.4)$ & $1(0.3)$ \\
\hline \multicolumn{6}{|l|}{ Interpersonal skills and communication skills } \\
\hline $\begin{array}{l}\text { Decreases learner-teacher interpersonal } \\
\text { relationship }\end{array}$ & $17(5.8)$ & $36(12.2)$ & $58(19.7)$ & $159(54.1)$ & $24(8.2)$ \\
\hline Decreases the teacher role & $17(5.8)$ & $44(15.0)$ & $54(18.4)$ & $147(50.0)$ & $32(10.9)$ \\
\hline Develops the team working skills & $54(18.4)$ & $214(72.8)$ & $16(5.4)$ & $8(2.7)$ & $2(0.7)$ \\
\hline Develops the communication skills & $48(16.3)$ & $221(75.2)$ & $17(5.8)$ & $7(2.4)$ & $1(0.3)$ \\
\hline Develops the unity in working group & $34(11.6)$ & $198(67.3)$ & $44(15.0)$ & $15(5.1)$ & $3(1.0)$ \\
\hline Increases the presentation skills & $44(15.0)$ & $227(77.2)$ & $21(7.1)$ & $2(0.7)$ & $0(0)$ \\
\hline \multicolumn{6}{|l|}{ Overall attitude toward PBL } \\
\hline \multirow{3}{*}{$\begin{array}{l}\text { Should implement PBL into clinical year } \\
\text { PBL is better than conventional } \\
\text { PBL is better than report writing }\end{array}$} & $68(23.1)$ & $161(54.8)$ & $43(14.6)$ & $21(7.1)$ & $1(0.3)$ \\
\hline & $25(8.5)$ & 98 (33.3) & 93 (31.6) & 67 (22.8) & $11(3.7)$ \\
\hline & 77 (26.2) & $108(36.7)$ & $58(19.7)$ & $43(14.6)$ & $8(2.7)$ \\
\hline
\end{tabular}

1 = Strongly Agree, 2 = Agree, 3 = Neither agree nor disagree, 4 = Disagree, 5 = Strongly Disagree

In regards to the attitudes of medical students toward the PBL (table1), most of them agreed that the knowledge according to the standards of medical competency were achieved (83.7\%), there was better knowledge retention than with conventional lectures $(74.2 \%)$, it has improved information inquiry skills $(89.1 \%)$, improved critical thinking skills (80.3\%), improved active learning (77.5\%)and promoted 
self-directed learning (91.5\%). Furthermore, regarding the impact of $P B L$ to the learner, the respondents have agreed that PBL improves the ability to express opinions (77.2\%), increases individual responsibility (78.5\%), increases self-study skills (88.4\%), improves listening skills $(91.4 \%)$ and improves leadership skills (78.9\%). However, $44.9 \%$ of the medical students are in disagreement that PBL reduces stress. Regarding interpersonal and communication skills, the medical students have agreed that $\mathrm{PBL}$ develops team working skills $(91.2 \%)$, develops communication skills (91.8\%), develops unity in working groups (91.2\%) and increases presentation skills $(92.2 \%)$. The respondents also have disagreed that the PBL decreases learnerteacher interpersonal relationships $(62.3 \%)$ and the teachers role $(60.9 \%)$.In regards to time effectiveness, they have agreed that PBL is time-efficient for the knowledge gained (67.4\%) although self-study is a time consuming process $(48.9 \%)$. They have disagreed that $\mathrm{PBL}$ sessions reduce the time for patient care $(56.7 \%)$.

When students have compared PBL with other learning tools, the medical students have agreed that $\mathrm{PBL}$ is better than conventional lectures (41.5\%) and report writing (62.9\%). They agreed that PBL should be implemented into clinical year curriculum with rate $77.9 \%$.

Concerning the understanding of PBL, $9.9 \%$ of the medical students scored 10 on a scale of 10 (table 2) and $76.5 \%$ were under the misunderstanding that PBL requires knowledge from conventional lectures (table 3). There were no statistical correlations between the students gender, the year of study, and GPA in regards to the attitudes and the understanding of PBL.

Table 2: The understanding scores of medical students toward PBL

\begin{tabular}{|c|c|}
\hline Scored & $\begin{array}{c}\text { Medical } \\
\text { students(\%) }\end{array}$ \\
\hline 10 & $29(9.9)$ \\
\hline 9 & $164(55.8)$ \\
\hline 8 & 56 (19.0) \\
\hline 7 & $25(8.5)$ \\
\hline 6 & $8(2.7)$ \\
\hline 5 & $5(1.7)$ \\
\hline 4 & $1(0.3)$ \\
\hline 3 & $3(1.0)$ \\
\hline 2 & $1(0.3)$ \\
\hline 1 & $2(0.7)$ \\
\hline Total & $294(100)$ \\
\hline
\end{tabular}

\section{Discussion}

This study has demonstrated that most of the medical students in their clinical year had a positive attitude toward the PBL strategy. They agreed that this instructional approach was effective for providing the knowledge and skills required for critical thinking, problem solving and self-directed learning. However, the general consensus was that PBL was time consuming. Furthermore, PBL also encourages a broad variety of abilities such as communication, team work, listening skills, presentations, information inquiry skills and responsibility. However, only $9.9 \%$ of the medical students were well informed about PBL concepts with a resulting score of $10 / 10$. Most of the medical students have misunderstood that PBL requires knowledge from conventional lectures. Given the fact that these medical students have had experiences in $\mathrm{PBL}$ sessions during their preclinical years, it may be interesting to further explore what they actually did in those PBL sessions. 
Table 3: The understanding of medical students toward PBL

\begin{tabular}{lccc}
\hline & $\begin{array}{c}\text { Agree } \\
(\%)\end{array}$ & $\begin{array}{c}\text { Disagree } \\
(\%)\end{array}$ & $\begin{array}{c}\text { Undecided } \\
(\%)\end{array}$ \\
\hline PBL is using a problem as a trigger to solve the problem by & $284(96.6)$ & $5(1.7)$ & $5(1.7)$ \\
seeking relevant knowledge & $232(78.9)$ & $36(12.2)$ & $26(8.8)$ \\
PBL develops the life-long learning skills & $274(93.2)$ & $12(4.1)$ & $8(2.7)$ \\
PBL is small group learning & $266(90.5)$ & $12(4.1)$ & $16(5.4)$ \\
PBL is student centered learning & $280(95.2)$ & $4(1.4)$ & $10(3.4)$ \\
PBL is the learning strategy that focus on critical thinking process & $225(76.5)$ & $54(18.4)$ & $15(5.1)$ \\
PBL is the learning strategies that required prior knowledge from & $262(89.1)$ & $12(4.1)$ & $20(6.8)$ \\
conventional lecture & $255(86.7)$ & $21(7.1)$ & $18(6.1)$ \\
PBL is the learning strategy that is multi-disciplinary integration & $282(95.9)$ & $5(1.7)$ & $7(2.4)$ \\
PBL is self-directed learning & $284(96.6)$ & $4(1.4)$ & $6(2.0)$ \\
PBL is the learning strategy that requires listening skills & 26.4 \\
PBL is the self-study & & &
\end{tabular}

Many factors are needed to facilitate a successful PBL program. There needs to be prior knowledge of the concept of PBL, the cooperation by the learners, proper resources and trained tutors (Newman, 2005). The positive attitudes and group effort are the most frequent factors which influence performance and learning in PBL (Morales-Mann \& Kaitell, 2001). The acceptance of the PBL philosophy is also associated with the motivation for using the PBL strategy which is crucial to successful learning (Ratzmann et al., 2013). Many reports have shown that the success of PBL requires a positive attitude and experience of the tutors (Hatthachote et al., 2008; Bernstein et al., 1995). Thus, the implementation of PBL pedagogy should be considered together in the light of the attitudes and knowledge of the learners and the faculty.

The PBL pedagogy has been implemented in the medical education curriculum for a few decades. It is usually used in the preclinical years to promote early clinical exposure.

Recently, modified PBL methods have been integrated into clinical education with the use of actual patients (Dammers et al., 2001). It is also used for students in their preclinical years with excellent results (Takkunen et al., 2011). Although the curriculum trends in medical education seem to be moving in the direction of self-directed learning and outcome-based learning, most medical student still appreciate conventional lectures. There are no good or bad techniques but some think there are thus making them so. Conventional lectures can be a vastly effective tool in the classroom, allowing the lecturer to provide interaction with their students, talking through difficult theories and refining difficult clinical decision-making choices.

Technological advances will replace higher education practices in use today (Sadeghi et al., 2014; Woo \& Kimmick, 2000). The integration of online lectures with PBL provides a new role for the instructor and will have a positive impact on student learning. This will allow the students to work with peers and instructors to apply and appraise a wealth of information that is readily accessible. PBL is not the total solution for education during the clinical year. Few studies have reported on the effects of PBL strategies for in the attainment of the goals of education during the clinical years. The combination of PBL strategies with other methods such as lecture-based learning, patient-based learning, report writing and clinical ward rounds could be augmenting the quality of the education. The provisions of critical reasoning and encouraging selfdirected learning skills necessary for lifelong learning are also important tactics to be utilized. A systematic review has shown that PBL has advantages in the development of physicians' competency after graduation. Some of these in particular are competencies in interpersonal dimension, cognitive domain and the development of more general, work-related skills (Koh et al., 2008; Schmidt et al., 2006).

In conclusion, medical students in their clinical years have positive attitudes toward PBL and the curriculums should combine PBL with other learning strategies. Knowledge of PBL, which is one of the key success factors, 
should prepare future physicians to help encourage their performance.

\section{Acknowledgments}

We would like to thank all participants. This research was supported by Faculty of Medicine, Srinakharinwirot University, Thailand

\section{Conflict of Interest: None declared}

\section{References}

Albanese, M. A. \& Mitchell, S. ( 1993) Problembased learning: a review of literature on its outcomes and implementation issues, Academic Medicine, 68, pp. 52-81.

Bernstein, P., Tipping, J., Bercovitz, K. \& Skinner, H. A. (1995) Shifting students and faculty to a PBL curriculum: attitudes changed and lessons learned, Academic Medicine, 70, 3, pp.245247.

Colliver, J. A. (2000)Effectiveness of problem-based learning curricula: research and theory, Academic Medicine, 75, pp. 259-266.

Dammers, J., Spencer, J. \& Thomas, M. ( 2001) Using real patients in problem-based learning: students' comments on the value of using real, as opposed to paper cases, in a problembased learning module in general practice, Medical Education, 35, 1, pp. 27-34.

Hartling, L., Spooner, C., Tjosvold, L. \& Oswald, A. (2010) Problem-based learning in pre-clinical medical education: 22 years of outcome research, Medical Teacher, 32, 1, pp. 28-35.

Hatthachote, P., Satayasai, W., Limratana, N., Kusumaphanyo, C., Ratanawilai, A., Wisedsook, N., Hetrakul, P. \& Maneechotirat, M. ( 2008) Medical instructor attitude and knowledge towards Problem-Based Learning, Royal Thai Army Medical Journal, 61, pp. 3-11.

Koh, G. C., Khoo, H. E., Wong, M. L. \& Koh, D. (2008) The effects of problem-based learning during medical school on physician competency: a systematic review, Canadian Medical Association Journal, 178, 1, pp. 34-41.
Lin, C. S. (2005) Medical students' perception of good PBL tutors in Taiwan, Teaching and Learning in Medicine, 17, 2, pp. 179-183.

Morales-Mann, E. T. \& Kaitell, C. A. ( 2001) Problem-based learning in a new Canadian curriculum. Journal of Advanced Nursing, 33, 1, pp. 13-19.

Nandi, P. L., Chan, J. N., Chan, C. P., Chan, P. \& Chan, L. P. ( 2000) Undergraduate medical education: comparison of problem-based learning and conventional teaching, Hong Kong Medical Journal, 6, 3, pp 301-306.

Newman, M. J. (2005) Problem Based Learning: an introduction and overview of the key features of the approach, Journal of Veterinary Medical Education, 32, 1, pp. 12-20.

Preeti, B., Ashish, A. \& Shriram, G. (2013) Problem Based Learning (PBL) - An Effective Approach to Improve Learning Outcomes in Medical Teaching, Journal of Clinical and Diagnostic Research, 7, 12, pp. 2896-2897.

Ratzmann, A., Wiesmann, U., Proff, P., Kordass, B. \& Gedrange, T. (2013) Student evaluation of problem-based learning in a dental orthodontic curriculum--a pilot study, GMS Zeitschrift für Medizinische Ausbildung, 30, 3, pp. Doc34.

Sadeghi, R., Sedaghat, M. M. \& Sha Ahmadi, F. (2014) Comparison of the effect of lecture and blended teaching methods on students' learning and satisfaction, Journal of advances in medical education and professionalism,2,4,pp.146-150.

Schmidt, H. G., Vermeulen, L. \& Van Der Molen, H. T. (2006) Long term effects of problem-based learning: a comparison of competencies acquired by graduates of a problem-based and a conventional medical school, Medical Education, 40, 6, pp 562-567.

Takkunen, M., Turpeinen, H., Viisanen, H., Wigren, H. K., Aarnio, M. \& Pitkaniemi, J. ( 2011) Introduction of real patients into problem-based learning in preclinical first-year anatomy curriculum,MedicalTeacher,33,10,pp.854-856.

Woo, M. A. \& Kimmick, J. V. (2000) Comparison of Internet versus lecture instructional methods for teaching nursing research, Journal of Professional Nursing, 16, 3, pp 132-139.

Wood, D. F. (2003) Problem based learning, British Medical Journal, 326, 7384, pp. 328-330. 